\title{
Radical prostatectomy for high-risk prostate cancer I Opinion: YES
}

\author{
Leonardo 0. Reis ${ }^{1,2}$, Rodrigo Montenegro ${ }^{3}$, Quoc-Dien Trinh ${ }^{3}$ \\ ${ }^{1}$ UroScience, Pontifícia Universidade de Campinas - PUC, Campinas, SP, Brasil; ${ }^{2}$ Departamento de \\ Urologia, Universidade Estadual de Campinas - UNICAMP, Campinas, SP, Brasil; ${ }^{3}$ Division of Urological \\ Surgery and Center for Surgery and Public Health, Brigham and Women's Hospital, Harvard Medical \\ School, Boston, MA, USA
}

Keywords: Prostatic Neoplasms; Prostatectomy; Radiotherapy

\section{INTRODUCTION}

Prostate cancer is the commonest non-skin malignancy in men. In most cases, prostate cancer has an indolent course however approximately 30,000 still die from the disease every year. Indeed, a subset of men will present with potentially lethal high-risk prostate cancer at diagnosis. We believe that this proportion will increase as fewer men are screened for prostate cancer, amidst ongoing concerns about overdiagnosis and overtreatment.

The American Urological Association - AUA defines high-risk prostate cancer as PSA $\geq 20 \mathrm{ng} / \mathrm{ml}$ or biopsy Gleason score $>7$ (ISUP Grade 4/5) or clinical T3. Patients with high-risk prostate cancer have different treatment options including radical prostatectomy (RP), external beam radiotherapy (EBRT) with androgen deprivation therapy (ADT) or EBRT plus brachytherapy $(\mathrm{BT})$ and $\mathrm{ADT}(1,2)$. For many years, EBRT has been the primary treatment option in this population, but the trend has been shifting towards more RP in the most contemporary era. While ideally the evidence should serve as a guide for treatment decisions, the reality of clinical practice is much more complex. Gray et al. showed that sociodemographic factors such as race, insurance and income have a strong influence on treatment choice (3). In parallel, the scientific evidence supporting surgery as part of the initial treatment protocol has been growing in the past decade, even though a sufficiently powered randomized clinical trial is lacking.

Patients are faced with a complex decision-making process when presenting with high-risk prostate cancer. While disadvantages of surgery for high-risk patients include perioperative risks and potentially worse quality of life, urinary and sexual toxicities, especially if patients require adjuvant EBRT+ADT, advantages of surgery for high-risk patients include accurate staging with immediate and excellent local control promoting accurate grading and staging, removal of benign sources of PSA guiding future therapy and possibly avoiding ADT, added to the potential of avoiding urinary (obstructive/irritative) and bowel toxicities and risk of secondary malignancies (4-6).

The comparative effectiveness of different treatment strategies for high-risk prostate cancer is a matter of intense debate. Wallis et al. conducted a meta-analysis of 118,830 patients 
evaluating the overall mortality and prostate cancer specific between patients treated with RP or radiotherapy. They found that radiotherapy for prostate cancer was associated with an increased risk of overall and prostate cancer-specific mortality compared with RP based on observational data with low to moderate risk of bias (7). In subgroup analyses, they found that the greatest benefit was observed among high-risk prostate cancer patients (HR: 1.83, 95\% CI: 1.51-2.22, $\mathrm{p}=0.0001$ ). Similarly, Petrelli et al., conducted a meta-analysis examining the survival outcomes among patients with only high-risk prostate cancer treated with RP or radiotherapy. They also found better overall and prostate cancer-specific survival for patients treated with surgery compared with radiotherapy. RP is associated with a $44 \%$ decreased risk of prostate cancer-specific mortality (HR: 0.56, 95\%CI: 0.37-0.85, $\mathrm{p}=0.007$ ) (8). Interestingly, a recent paper by Ennis et al., relying on data from the National Cancer, showed that there was no difference in overall survival between patients treated with RP versus EBRT plus BT with or without ADT while EBRT plus ADT was associated with lower survival (9). However, another study relying on the same dataset, limited to younger and healthy men (to limit the risk of other cause mortality as this dataset does not identify the cause of death) presenting with high-risk localized prostate cancer, Berg et al. observed that RP was associated with a statistically significant overall survival benefit compared to EBRT plus BT (10) (HR (EBRT plus BT compared to RP): 1.22, 95\% CI: $1.05-$ 1.43). However, it is still important to acknowledge, as surgeons, that patients treated with RT are very different from those treated with surgery and residual confounding cannot be excluded. Moreover, most studies are biased by retrospective design or underpowered to draw any conclusion on the efficacy of the treatments (11-14), which also undermine the conclusions of the available meta-analyses, limited to observational studies $(7,8)$.

A key benefit of surgery is to provide more accurate staging, as well as prognostic information (15). A problem of broad all-encompassing diagnostic categories is that some patients have much more aggressive disease than others, even within the same risk stratification group. A patient presenting with a single core of Gleason $4+4$ prostate cancer likely has a different prognosis than a patient presenting with Gleason $5+5$ prostate cancer in all cores invading both seminal vesicles on imaging. Specifically, a study showed that $60 \%$ of patients with a biopsy Gleason score 8 was downgraded following radical prostatectomy (1). Another concern is that many cases that improvements in imaging techniques such as the MRI has led to a higher proportion of men diagnosed with clinical stage T3 disease - while these patients are obviously at a higher risk of recurrence and/or need for adjuvant EBRT+ADT, it would be unfair to say that the prognosis of such patients is the same as clinical T3 disease found on the basis of a digital rectal exam. For such cases, and many others, RP offers the hope of cure with surgery alone, potentially avoiding the toxicities of prolonged ADT, which for many, are more severe than toxicities of RT. Indeed, $\mathrm{ADT}$ is associated with a plethora of quality of life affecting, and potentially life-threatening side-effects such as: metabolic syndrome, cardiovascular toxicities (16), cognitive dysfunction (17), liver disease (18), osteoporosis, etc. Even among those who are not cured with surgery alone, the duration of adjuvant ADT (given with EBRT) in the setting of adverse features at RP is manifold shorter than the ADT accompanying EBRT as a first-line treatment for high-risk prostate cancer.

\section{CONCLUSIONS}

While we fully acknowledge the limitations of the retrospective data cited in the current review (19), we believe that there is more than enough data to support RP as a first-line treatment for high-risk prostate cancer in the right surgical candidate. Given the lack of level 1 evidence, it is important to discuss the pros and cons of each treatment option (RP vs EBRT+BT+ADT vs. EBRT+ADT) in a multidisciplinary setting. It is also important to acknowledge that novel treatment approaches centered around 
surgery are being tested as we speak - for example the use of neoadjuvant androgen deprivation therapy prior to RP for high-risk prostate cancer, using next generation molecules, is the subject of several ongoing trials (20-23).

\section{ACKNOWLEDGEMENTS}

Quoc-Dien Trinh is supported by the Brigham Research Institute Fund to Sustain Research Excellence, the Bruce A. Beal and Robert L. Beal Surgical Fellowship, the Genentech Bio-Oncology Career Development Award from the Conquer Cancer Foundation of the American Society of Clinical Oncology, a Health Services Research pilot test grant from the Defense Health Agency, the Clay Hamlin Young Investigator Award from the Prostate Cancer Foundation and an unrestricted educational grant from the Vattikuti Urology Institute.

Leonardo 0. Reis is supported by National Council for Scientific and Technological Development - CNPq, Research Productivity: 304747/2018-1 and CAPES Foundation, grant: 23038.005289/2017-88 / PREMIO 443/2017

\section{CONFLICT OF INTEREST}

Quoc-Dien Trinh reports honoraria from Astellas, Bayer, InsighTec, Intuitive Surgical and Janssen.

\section{REFERENCES}

1. Gansler T, Fedewa S, Qi R, Lin CC, Jemal A, Moul JW. Most Gleason 8 Biopsies are Downgraded at ProstatectomyDoes 4 + 4 = 7? J Urol. 2018;199:706-12.

2. Hu JC, Nguyen P, Mao J, Halpern J, Shoag J, Wright JD, et al. Increase in Prostate Cancer Distant Metastases at Diagnosis in the United States. JAMA Oncol. 2017;3:705-7. Erratum in: JAMA Oncol. 2017;3:709.

3. Gray PJ, Lin CC, Cooperberg MR, Jemal A, Efstathiou JA. Temporal Trends and the Impact of Race, Insurance, and Socioeconomic Status in the Management of Localized Prostate Cancer. Eur Urol. 2017;71:729-37.
4. Meng MV, Elkin EP, Latini DM, Duchane J, Carroll PR. Treatment of patients with high risk localized prostate cancer: results from cancer of the prostate strategic urological research endeavor (CaPSURE). J Urol. 2005;173:1557-61.

5. Feldman AS, Meyer CP, Sanchez A, Krasnova A, Reznor G, Menon M, et al. Morbidity and Mortality of Locally Advanced Prostate Cancer: A Population Based Analysis Comparing Radical Prostatectomy versus External Beam Radiation. J Urol. 2017;198:1061-8.

6. Nam RK, Cheung P, Herschorn S, Saskin R, Su J, Klotz $\mathrm{LH}$, et al. Incidence of complications other than urinary incontinence or erectile dysfunction after radical prostatectomy or radiotherapy for prostate cancer: a population-based cohort study. Lancet Oncol. 2014;15:223-31.

7. Wallis CJD, Saskin R, Choo R, Herschorn S, Kodama RT, Satkunasivam R, et al. Surgery Versus Radiotherapy for Clinically-localized Prostate Cancer: A Systematic Review and Meta-analysis. Eur Urol. 2016;70:21-30.

8. Petrelli F, Vavassori I, Coinu A, Borgonovo K, Sarti E, Barni S. Radical prostatectomy or radiotherapy in high-risk prostate cancer: a systematic review and metaanalysis. Clin Genitourin Cancer. 2014;12:215-24.

9. Ennis RD, Hu L, Ryemon SN, Lin J, Mazumdar M. Brachytherapy-Based Radiotherapy and Radical Prostatectomy Are Associated With Similar Survival in High-Risk Localized Prostate Cancer. J Clin Oncol. 2018;36:1192-8.

10. Berg S, Cole AP, Krimphove MJ, Nabi J, Marchese M, Lipsitz SR, et al. Comparative Effectiveness of Radical Prostatectomy Versus External Beam Radiation Therapy Plus Brachytherapy in Patients with High-risk Localized Prostate Cancer. Eur Urol. 2019;75:552-5.

11. Lennernäs B, Majumder K, Damber JE, Albertsson P, Holmberg E, Brandberg Y, et al. Radical prostatectomy versus high-dose irradiation in localized/locally advanced prostate cancer: A Swedish multicenter randomized trial with patient-reported outcomes. Acta Oncol. 2015;54:875-81.

12. Stewart SB, Boorjian SA. Radical prostatectomy in high-risk and locally advanced prostate cancer: Mayo Clinic perspective. Urol Oncol. 2015;33:235-44.

13. Tyson MD 2nd, Koyama T, Lee D, Hoffman KE, Resnick MJ, Wu XC, Cooperberg MR, et al. Effect of Prostate Cancer Severity on Functional Outcomes After Localized Treatment: Comparative Effectiveness Analysis of Surgery and Radiation Study Results. Eur Urol. 2018;74:26-33.

14. Kishan AU, Cook RR, Ciezki JP, Ross AE, Pomerantz MM, Nguyen PL, et al. Radical Prostatectomy, External Beam Radiotherapy, or External Beam Radiotherapy With Brachytherapy Boost and Disease Progression and Mortality in Patients With Gleason Score 9-10 Prostate Cancer. JAMA. 2018;319:896-905. 
15. Reis LO, Nguyen PL. Prostate Cancer - Local Treatment after Radiorecurrence: Surgery - Back to the future? Int Braz J Urol. 2018;44:433-4.

16. Sun M, Choueiri TK, Hamnvik OP, Preston MA, De Velasco G, Jiang W, et al. Comparison of Gonadotropin-Releasing Hormone Agonists and Orchiectomy: Effects of AndrogenDeprivation Therapy. JAMA Oncol. 2016;2:500-7.

17. Sun M, Cole AP, Hanna N, Mucci LA, Berry DL, Basaria $S$, et al. Cognitive Impairment in Men with Prostate Cancer Treated with Androgen Deprivation Therapy: A Systematic Review and Meta-Analysis. J Urol. 2018;199:1417-25.

18. Gild P, Cole AP, Krasnova A, Dickerman BA, von Landenberg N, Sun M, et al. Liver Disease in Men Undergoing Androgen Deprivation Therapy for Prostate Cancer. J Urol. 2018;200:573-81.

19. Wallis CJD, Nam RK. Reply from Authors re: Martin Spahn, Alan Dal Pra, Daniel Aebersold, Bertrand Tombal. Radiation Therapy Versus Radical Prostatectomy: A Never-ending Discussion. Eur Urol 2016;70:31-2: Prostate Cancer Treatment: Take Out the Emotion, Please. Eur Urol. 2016;70:33-34.

20. Chun J, Pruthi RS. Is neoadjuvant hormonal therapy before radical prostatectomy indicated? Urol Int. 2004;72:275-80.

21. McKay RR, Montgomery B, Xie W, Zhang Z, Bubley GJ, Lin DW, et al. Post prostatectomy outcomes of patients with high-risk prostate cancer treated with neoadjuvant androgen blockade. Prostate Cancer Prostatic Dis. 2018;21:364-72.
22. McKay RR, Ye H, Xie W, Lis R, Calagua C, Zhang Z, et al. Evaluation of Intense Androgen Deprivation Before Prostatectomy: A Randomized Phase II Trial of Enzalutamide and Leuprolide With or Without Abiraterone. J Clin Oncol. 2019;37:923-31.

23. McClintock TR, von Landenberg N, Cole AP, Lipsitz SR, Gild P, Sun M, et al. Neoadjuvant Androgen Deprivation Therapy Prior to Radical Prostatectomy: Recent Trends in Utilization and Association with Postoperative Surgical Margin Status. Ann Surg Oncol. 2019;26:297-305.

Correspondence address:

Leonardo 0. Reis MD, MSc, $\mathrm{PhD}$

UroScience, Pontifícia Universidade de Campinas PUC Campinas, Rua Professor Dr. Euryclides de Jesus Zerbini, 1516 Parque Rural Fazenda Santa Cândida Campinas, SP, 13087-571, Brasil E-mail: reisleo.1@gmail.com

ARTICLE INFO

Reis $L O$

https://orcid.org/0000-0003-2092-414X

Int Braz J Urol. 2019; 45: 424-7

Submitted for publication: April 15, 2019

Accepted after revision: May 02, 2019

Published as Ahead of Print: May 10, 2019 